\title{
Espaço, Lugar e Sentidos: Homossexualidade, Consumo e Produção de Subjetividades na Cidade de São Paulo
}

\author{
Space, Place and Meaning: Homosexuality, Consumption and Production of \\ Subjectivities in the City of São Paulo
}

\author{
Isadora Lins França \\ Núcleo de Estudos de Gênero Pagu / Unicamp \\ isa.linsf@gmail.com
}

\section{Resumo}

Neste artigo $^{1}$ abordo as relações entre lugares, consumo e produção de subjetividades, tomando como foco um contexto de segmentação do mercado de lazer noturno frequentado por homens que se relacionam afetivo - sexualmente com outros homens na cidade de São Paulo. A pesquisa, de metodologia qualitativa, contou com observação etnográfica e entrevistas e se desenrolou a partir de um recorte num conjunto mais amplo de espaços de sociabilidade. Uma grande boate de música eletrônica, uma festa e um samba GLS foram selecionados como lugares - chave e analisados comparativamente de acordo com os sentidos que lhes conferem seus frequentadores. A intersecção entre marcadores sociais da diferença, tais como gênero, sexualidade, classe social, cor/raça e idade, e o modo como operam na constituição dos lugares e de subjetividades relacionadas a esses lugares também foram levados em conta na análise.

Palavras chave: espaço; lugar; sexualidade; gênero; consumo.

\begin{abstract}
This article approaches the relations among places, consumption and production of subjectivities in the context of the segmentation of nightlife market targeted to men who like other men, in the city of São Paulo. The research is based on a qualitative methodology, with ethnographic observations and in depth interviews. It was developed focusing on the selection of three venues among a bigger circuit of venues related to gay men in the city. A big club, a party and a samba place were selected as key - places and compared in regard of the meanings which are given them by their customers. The intersection among social markers of difference and how they act in the constitution of places and subjectivities related to these places were also considered in the analysis.
\end{abstract}

Keywords: Space; Place; Sexuality; Gender; Consumption. 


\section{Introdução}

'A diferença está dentro do mundo gay', disse-me um dos interlocutores da pesquisa que da origem a este trabalho, numa noite quente de março de 2008. Essa era uma máxima que Rodrigo havia aprendido pela sua própria experiência como um rapaz jovem, negro, de classes populares, que havia se mudado de um bairro distante da cidade para o centro: a frase remetia ao constante deslocamento que marcava sua trajetória e ao fato de se sentir sempre diferente. Sendo obrigada a concordar com meu interlocutor, devo adicionar que, se a 'diferença está dentro do mundo gay', apresenta-se de forma singular e multifacetada. São os intrincados processos de diferenciação e subjetivação relacionados ao consumo e à homossexualidade na sua dimensão plural que busquei apreender naquela pesquisa. Procurei me aproximar desses temas abordando a produção de subjetividades, categorias identitárias e estilos relacionados à homossexualidade, num contexto de segmentação de mercado, a partir de um recorte no conjunto de espaços de sociabilidade e consumo frequentados por homens que se relacionam afetivo sexualmente com outros homens ${ }^{2}$, na cidade de São Paulo.

Neste texto, articulo a ideia de que os lugares de sociabilidade e as práticas de consumo - deles e neles - estão marcados pelas singularidades do contexto de segmentação de mercado que se firma nas duas últimas décadas. No que concerne ao mercado relacionado à homossexualidade, não apenas verifica-se um aumento do número de estabelecimentos que compunham o antigo 'gueto' paulistano e uma nova profusão de categorias de identidade, mas também, uma transformação mais incisiva em direção à diversificação de iniciativas comerciais conectadas aos seus respectivos públicos, uma maior visibilidade $\mathrm{e}$ uma ocupação mais variada no espaço urbano. Os empreendimentos voltados para o lazer noturno ainda figuram como centrais nesse cenário, não obstante a considerável diversificação de serviços e a proliferação de lugares de encontro virtuais. Esses últimos oferecem possibilidades importantes de busca de parceiros e aliam-se aos espaços de sociabilidade na divulgação de estratégias comerciais e intensificação e prolongamento das relações travadas nos lugares, mais do que competem com eles.

Néstor Perlongher, escrevendo nos anos 1980, a respeito do 'gueto gay paulistano', remete a um contexto em que "processos de diferenciação social entre as populações homossexuais" não estavam imediatamente relacionados a uma "lógica do consumo" (PERLONGHER, 1987, p. 117), embora, já naquele momento, fosse possível visualizar certa diversidade de estilos e categorias de identidade. Parte da minha proposta de pesquisa era, mais de 20 anos depois, tentar compreender qual o papel atualmente desempenhado pelo consumo nesses processos de diferenciação social, considerando os desenvolvimentos recentes de um mercado ao qual Perlongher teve acesso em período mais incipiente.

Peter Fry (2002), no seu trabalho sobre o mercado de produtos de beleza direcionados a "pessoas de pele mais escura e cabelo mais crespo", defende, concordando com Marshall Sahlins (2000), que, ao contrário do que os produtores acreditam, tal mercado não se constitui em resposta às demandas de uma classe média negra, mas integra um processo de constituição mesmo dessa classe média. Como afirma o autor, os "bens e serviços não apenas suprem uma necessidade; na verdade, criam uma necessidade e, ao fazê-lo, disseminam sub-repticiamente uma 'identidade negra' em todo o Brasil'" (FRY, 2002, p. $315)$.

Na mesma direção de Fry, acredito que o mercado voltado para gays não responde à demandas de um 'grupo social pré-existente', mas contribui para a produção mesma de sujeitos, categorias de identidade e estilos, perspectiva que organiza minha proposta e as perguntas que direcionei à pesquisa que dá origem a este artigo. Procurei compreender como se articulam marcadores de diferença - como gênero, sexualidade, classe, idade e cor/raça - atuantes na produção de sujeitos, categorias e estilos relacionados à homossexualidade e como a prática do consumo, seja nos ou dos lugares que serviram de base para a observação etnográfica, media essa articulação. Tenho para mim que essas duas pontas do consumo - dos ou nos lugares - estão intimamente articuladas: longe de serem apenas cenários neutros, os lugares atuam na constituição de subjetividades ao mesmo tempo em que são constituídos pelos seus frequentadores; por outro lado, funcionam também como contextos que revelam e possibilitam determinados usos de bens ou que fazem circular informações a seu respeito, estimulando ou não o interesse por objetos ou práticas de consumo específicos. Neste artigo, porém, concentrarei minha atenção numa das pontas desse processo: a partir de uma discussão sobre espaço, lugar e sentidos de lugar e sobre consumo e segmentação no setor de lazer noturno, passo a contrapor os lugares que foram observados no decorrer da pesquisa de campo tendo como base notas etnográficas e trechos de entrevistas em que meus interlocutores produzem contrastes entre diferentes lugares. 


\section{Pensando Espaço e Lugar}

Procurei incorporar algumas discussões recentes na área da Geografia e ciências sociais, de modo geral, no que elas podem se cruzar com uma abordagem antropológica, marcada por uma perspectiva relacional e pela atenção central conferida à dimensão simbólica do espaço. Na década de 1990, uma perspectiva espacial ganha impulso na discussão sobre consumo nas Ciências Sociais, numa produção marcada pela interdisciplinaridade e pela análise da dimensão concreta - ou material - do espaço e da sua dimensão simbólica, ou seja, de como os lugares são significados e como as pessoas também se constituem por meio dos lugares (MANSVELT, 2005; JACKSON e THRIFT, 1995; MCDOWELL, 1997).

Diferentes autores têm enfatizado a pertinência da ideia de lugar, estabelecendo bases para a sua definição que não repousam na fixação de fronteiras ou numa atribuição de sentido relacionada à estabilidade e homogeneidade, mas sim na consideração de que as fronteiras dos lugares são maleáveis e abertas e de que complexas interconexões os ligam uns aos outros (MASSEY, 1995, MCDOWELL, 1997, GUPTA e FERGUSON, 2000).

Vale destacar, aqui, a contribuição de geógrafas feministas que, em articulação com os estudos de gênero, elaboraram uma crítica à noção de lugar, sustentando que diferentes lugares ganham significado também diferenciado a partir de marcadores como gênero, cor/raça, idade, sexualidade e classe social, entre outros (MCDOWELL, 1997). Assim, ainda que consideremos a produção de uma 'comunidade imaginada' (ANDERSON, 2008) em torno de preferências sexuais ${ }^{3}$, implicando lugares de sociabilidade, não podemos supor que todos os outros marcadores sociais de diferença podem ser subsumidos a partir da sexualidade. A articulação entre os marcadores sociais de diferença produzem não só posições de sujeito diversas, mas também sentidos diversos de lugar ${ }^{4}$.

Pensar os sentidos de lugar é fundamental para articular as dimensões simbólicas, que permitem afirmar que um lugar pode ser consumido, já que uma das definições de consumo diz respeito à fase em que os bens deixam de ser "bens neutros, que poderiam pertencer a e ser identificados com qualquer um, e se tornam atributos de alguma personalidade individual, insígnias de identidade ou significantes de relacionamentos e compromissos interpessoais específicos" (GELL, 2008, p. 146). Nessa direção, podemos dizer que estabelecimentos comerciais podem ser consumidos na medida em que oferecem acesso à ambientes aos quais são atribuídos significados particulares pelas pessoas.

Ainda assim, os estudos que abordam o consumo de lugares na Geografia têm se voltado, em sua maioria, para espaços tidos como 'espetaculares' (como parques temáticos) ou para espaços construídos com o objetivo de proporcionar um cenário ideal para o consumo de bens (como shopping centers e lojas de departamento). Destoando um pouco desses estudos, há trabalhos que se dedicaram a pensar os significados atribuídos ao espaço doméstico e como eles podem ser relacionados a práticas de consumo; outros se dedicaram ao ciberespaço, procurando compreender como seus consumidores produzem sociabilidades e identidades particulares, entre o real e o virtual, e como a internet produz novas práticas e lugares para o consumo $^{5}$. Tem sido mais comum na literatura, no entanto, abordar as práticas de consumo que se desenrolam nos lugares, em vez do consumo dos lugares em si, ou seja, dos significados atribuídos aos lugares por seus frequentadores e de como eles estão implicados no consumo dos serviços e das experiências que os diferentes lugares proporcionam ${ }^{6}$. Essa escassez de estudos revela um terreno permeável a experimentações no que diz respeito à construção de ferramentas de análise e suportes teóricos que, se por um lado dificulta o trabalho, por outro, abre espaço para que se possam tatear diferentes caminhos.

Entretanto, se podemos dizer que estabelecimentos comerciais podem ser consumidos na medida em que oferecem acesso a ambientes aos quais são atribuídos significados particulares pelas pessoas, não esgotamos aí a relação entre consumo, subjetividades e espaço. John Urry observa que não só lugares podem ser consumidos, mas que "são cada vez mais centros para o consumo, provendo o contexto no qual bens e serviços são comparados, avaliados, adquiridos ou usados" (URRY, 1995, p. 1). Do modo como concebi o arranjo da pesquisa, considero que tratamos de espaços, pessoas e experiências que também implicam objetos ${ }^{7}$.

\section{Situand o Processos no Mercad o: Lazer Noturno e Segmentação}

O significado adquirido por um lugar sempre é produzido a partir das relações com outros lugares e com outras pessoas. Doreen Massey afirma que, "em vez de pensar os lugares como áreas com fronteiras ao redor, pode se imaginá-los como momentos articulados em redes de relações e entendimentos sociais" (MASSEY, 2000, p. 184). Gupta e Ferguson (2000) propõem uma abordagem do significado de um lugar específico como um processo, a partir da intersecção entre a construção cultural do lugar e sua localização 
em meio a um 'sistema de espaços hierarquicamente organizados', cujo funcionamento não está atado nem à 'contiguidade territorial' nem ao 'contato pessoal'. Os significados assumidos pelos lugares - e por consequência o estabelecimento de fronteiras - não são nunca 'puros', mas sempre construídos em conexão. Lugares são, pois, sempre híbridos, interligados e dotados de fronteiras porosas (MASSEY, 1995). Se os lugares incorporados à pesquisa de campo são únicos nos sentidos que adquirem como espaços físicos marcados por interações singulares, nenhum deles pode ser interpretado como tendo fronteiras fechadas, pois se constituem também por meio da capacidade dos seus frequentadores de relacioná-los a outros lugares, dos quais se tem uma experiência física ou mesmo imaginada.

Durante a pesquisa, um repertório de lugares, identificado com homens que se relacionam afetivo/sexualmente entre si, era frequentemente acionado pelos entrevistados, figurando como possibilidades de encontrar parceiros, de se engajar em atividades de sociabilidade com outros homens que partilhariam preferências sexuais semelhantes e de fruição de um ambiente público em que demonstrações de afeto entre homens são permitidas. Esse conjunto de lugares, contudo, não necessariamente corresponde à totalidade de lugares relacionados à homossexualidade na cidade, ou aos que aparecem nos guias e roteiros gays: é sempre um repertório acionado de maneira diferente em variadas situações. Uma situação de entrevista para uma pesquisa, portanto, pode trazer a lembrança de lugares que não entrariam em pauta na situação de escolha de onde ir com os amigos numa sexta-feira à noite: para um entrevistado frequentador do samba GLS, por exemplo, a experiência em outras boates era acionada na constituição de um repertório de lugares conhecidos que auxiliasse na tarefa de produzir contrastes que marcariam o samba GLS como lugar. As boates mencionadas, entretanto, eram acessadas muito raramente e não faziam parte das opções de lazer do fim de semana.

O que mobiliza a leitura das falas dos entrevistados é entender como eles atribuem significado aos lugares, relacionando-os entre si, e como articulam isso em torno de identificações e diferenciações com esses lugares, mais do que dar conta de todos os possíveis itinerários e lugares relacionados à homossexualidade na cidade. Tais significados ajudam a nos aproximar de como meus interlocutores, a partir de diferentes posições de sujeito, compreendem processos de diferenciação no contexto de segmentação de mercado e de como produzem fronteiras, aproximações e sentimentos de pertencimento relacionados a lugares comerciais de lazer noturno. Interessa, aqui, a compreensão de processos de produção de diferenças a partir de "espaços comuns, compartilhados e conectados" (GUPTA e FERGUSON, 2000, p. 43), mais do que a análise de diferenças irredutíveis entre os lugares e as pessoas que os frequentam.

Frank Mort, escrevendo a respeito dos estilos de masculinidade, nas décadas de 1980 e 1990 em Londres, ressalta a importância de uma "matriz espacial" em que "lugar, cenário e contexto" informam e atuam na constituição de diferentes "formas comerciais de masculinidade" (MORT, 1996, p. 150). $\mathrm{O}$ autor ressalta que o espaço não é um pano de fundo passivo a ser ocupado por sujeitos plenamente constituídos, mas atua na constituição de subjetividades mediadas pelo consumo, congregando práticas de consumo que se organizam espacialmente. $\mathrm{Na}$ sua análise do Soho, bairro londrino, com uma intensa ocupação por estabelecimentos voltados para homossexuais e para um público mixed, Mort ressalta como as casas noturnas exerceram papel preponderante, ajudando a pluralizar a ocupação do espaço a partir da fixação de ambientes heterogêneos, voltados para públicos masculinos específicos, o que resultava também em constante negociação entre diferentes estilos de masculinidade. Assim, uma tendência à segmentação desempenhou papel fundamental na multiplicação de estilos relacionados à homossexualidade e à masculinidade de forma geral, que se encontravam e eram negociados no bairro do Soho pelo contato entre os frequentadores de estabelecimentos de lazer noturno.

$\mathrm{O}$ processo de segmentação de mercado identificado por Mort, no caso do Soho, não é fenômeno isolado de movimentos mais abrangentes envolvendo processos de diferenciação relacionados ao consumo e, mais especificamente, ao consumo de serviços voltados para o lazer e a vida noturna. Os lugares não fogem a essa lógica: como ressalta Mort, responderiam à multiplicação de estilos relacionados ao consumo, bem como, colocariam em movimento esses estilos, atuando na sua constituição.

Por outro lado, a segmentação de estabelecimentos de lazer noturno também está relacionada ao lugar ocupado por esses estabelecimentos no cotidiano de grandes cidades. Hollands e Chatterton (2003) apontam como a vida noturna (nightlife) relacionada ao entretenimento vem se desassociando da ideia de criminalidade, prazeres liminares e marginalidade, aparecendo integrada ao crescimento urbano, legitimada por investimentos públicos e privados. Os autores localizam quatro amplos traços no que denominam de 'nova economia da vida noturna': globalização, $\quad$ corporatization $^{8}$, atribuição/desenvolvimento de marca (branding) e 
segmentação de mercado. De alguma forma, esses traços estavam presentes nos lugares que observei, embora se distribuíssem de forma e com intensidade diferenciada. Ganhavam muitíssimo mais ênfase em empreendimentos como a The Week, por exemplo, que atendia a um volume muito grande de pessoas e movimentava valores muito maiores do que os outros lugares observados, construindo estratégias específicas de lançamento no mercado internacional, de desenvolvimento da marca e de profissionalização do serviço oferecido e de melhorias constantes e de grande porte na infraestrutura do estabelecimento.

Embora o processo de segmentação de mercado ${ }^{9}$ seja apenas um dos pontos sublinhados por Hollands e Chatterton $(2003)^{10}$, no que diz respeito à 'nova economia da vida noturna', este aspecto apareceu na pesquisa como responsável por um impacto profundo na experiência de consumo dos lugares. O processo de diferenciação dos estabelecimentos e de direcionamento do seu público, que tem se mostrado cada vez mais intenso nas últimas décadas, parece ter um impacto considerável nos padrões de frequência aos lugares: se é verdade que as pessoas circulam por lugares os mais diversos por motivos vários, as falas que obtive em campo, assim como a observação, me permitem afirmar que há também uma tendência à fixação a certos lugares, relacionada a uma ideia de pertencimento e de adequação ao ambiente, bem como uma sempre crescente diversidade de lugares direcionados a públicos diferentes ${ }^{11}$.

Considero o âmbito do consumo como um meio privilegiado na direção de evidenciar a crescente complexificação de categorias classificatórias e identificações, que marca a experiência de homens, que se relacionam afetivo/sexualmente com outros homens, numa grande cidade como São Paulo e que se traduz na própria segmentação desse mercado. Arrisco dizer que esse processo de segmentação é produzido: 1) pelas diferenciações sociais entre homens que se relacionam afetivo/sexualmente com outros, em termos de estilo e gosto e pela diversificação de lugares possíveis, pelos quais essas pessoas podem se reconhecer como participantes de uma 'comunidade imaginada' (ANDERSON, 2008); 2) pelos cortes relacionados à classe social, gênero, sexualidade, geração e cor/raça na produção do desejo ${ }^{12}$; 3 ) por fim, responde a dinâmicas próprias do mercado, que acompanham diferenciações sociais já existentes, e ao mesmo tempo ajudam a cristalizar e a aprofundar essas diferenciações.

A combinação entre a construção de ambientes, que sejam sinônimos de experiências de consumo singulares, dos estilos e públicos que atendem e de aproximações e distanciamentos, em relação a outros estabelecimentos, parece ser fundamental no processo de diferenciação dos lugares e de segmentação do mercado de lazer noturno em São Paulo, bem como na circulação das pessoas pelos diferentes lugares. A seguir, apresento com mais detalhes os três lugares que são foco deste trabalho, procurando entender, a partir dos discursos observados em campo, como os significados associados a eles são produzidos relacionalmente ${ }^{13}$. Procuro articular uma análise dos significados atribuídos aos lugares da pesquisa pelos seus frequentadores e pelos frequentadores de outros lugares, sem perder de vista uma teia mais ampla que revele como esses lugares constituem-se, por meio de relações entre si, que também são relações de poder.

\section{Lugares Chave}

Selecionei três lugares para a pesquisa de campo, que denominei de lugares chave, dedicando-me à observação etnográfica e à aproximação com interlocutores que me indicassem quais sentidos atribuem a esses lugares. Inicialmente, a ideia era congregar um número maior de lugares, escolhidos a partir de um campo prévio. No decorrer da pesquisa, porém, esse arranjo mostrou-se apenas um ponto de partida, já que, a possibilidade de conduzir uma observação mais aprofundada e uma experiência de pesquisa mais densa tornou-se muito mais atraente que uma espécie de mapeamento. Uma das opções seria concentrar meu campo em apenas um lugar de pesquisa, percorrendo os itinerários realizados por meus interlocutores e compreendendo de forma mais focada suas experiências em diferentes situações e os sentidos atribuídos aos diferentes espaços percorridos. Isso foi realizado, em parte, mas escolhi dedicar-me à dimensão comparativa que o campo em diferentes lugares seria capaz de prover $^{14}$.

Os lugares que observei durante a pesquisa foram a The Week, uma grande boate de música eletrônica; a Ursound, uma festa voltada para ursos (grosso modo, podem se definidos como homens gays, gordos e peludos) e seus admiradores; e o Boteco do Caê, que é um samba GLS. Todos eram espaços comerciais, direcionados para homens que se relacionam afetivo/sexualmente com outros homens, e foram selecionados levando em conta o quanto me pareciam analiticamente interessantes, a partir da possibilidade de revelarem interseccionalidades e diferenças num terreno que já era meu velho conhecido desde o mestrado (FRANÇA, 2006). Além disso, a ideia de contrapor processos de produção de diferença a partir do consumo foi fundamental para a seleção de lugares que não tivessem conexões explícitas entre si, que não partilhassem o mesmo público e que se posicionassem 
diferentemente em termos de visibilidade. Se a The Week, e todo o burburinho que a acompanhava (blogs, revistas), parecia se integrar a um processo de produção de um estilo gay, que tem grande visibilidade - e que talvez seja responsável pela produção de uma identidade gay celebrada pela mídia -, lugares como o samba GLS e as festas dos ursos pareciam estar dialogando com versões de homossexualidade menos festejadas. Um dos meus intuitos era que cada uma das etnografias e que a pesquisa em cada um dos diferentes lugares pudessem servir constantemente de contraponto aos outros, evitando generalizações e iluminando singularidades.

\section{The Week, Ursound e Boteco do Caê: sentid os de lugar}

Um ponto importante a se considerar, quando pensamos em como diferentes lugares estão imersos em relações de poder, diz respeito aos fluxos de informações que os atravessam e à capacidade de seus frequentadores e proprietários de manejar e fazer circular informações sobre o lugar e sobre si mesmos, bem como produzir espaços que sejam vistos como 'representativos' de ideias relacionadas à 'homossexualidade'. Há um intenso fluxo de informações que passa por cidades como Nova York, Londres, Berlim, Barcelona, entre outras, que produz significados - em grande parte positivos - associados aos gays e que são acionados na atribuição de sentido, relacionados aos lugares de lazer noturno. Essas informações chegam primeiro às pessoas que poderíamos qualificar como 'intermediários culturais' (FEATHERSTONE, 1995) ${ }^{15}$, conectadas às tecnologias e redes de informação e responsáveis por antecipar tendências, em termos de consumo e estilo, muitas vezes, posteriormente, popularizadas. Assim, produzem-se aparentes 'consensos' em torno dos estilos associados aos gays e que se materializam nos espaços de lazer noturno - incluindo desde o consumo de determinadas roupas até os tipos de psicoativos articulando também conteúdos relacionados a marcadores de classe social, idade, cor/raça, gênero e sexualidade.

Entre os lugares da pesquisa, a The Week aparecia como a realização desses 'consensos': ali, haveria uma maior sintonia com as modas associadas aos gays e a reprodução de imagens que reforçam certos padrões de consumo. Um fator fundamental era a visibilidade adquirida pelo estabelecimento: era quase obrigatória a sua presença nos principais guias e roteiros de lazer da cidade, fossem eles da mídia segmentada ou não. $\mathrm{Na}$ internet, era visibilizada por muitos sites e blogs como a mais importante boate gay do país, além de ser a maior delas ${ }^{16}$. Sua visibilidade era aumentada, ainda, pelas filiais no Rio de Janeiro e da The Week Floripa e pelos projetos internacionais, em que sua marca era responsável pela promoção de festas na Europa.

Tanta exposição, além do volume do empreendimento $^{17}$, fazia com que a boate tenha sido a mais citada em todas as entrevistas, como se houvesse selado um padrão ao qual fosse necessário remeter quando o assunto remete aos lugares relacionados à homossexualidade, seja para criticar ou para afirmar esse padrão. Assim, os significados associados à The Week estavam sempre relacionados a um padrão de excelência no setor de serviços voltados para o público gay e à melhor realização do formato de boate de que se tem notícia, por um lado, e à produção de normatividades que geram adesão ou recusa, por outro lado.

A fala abaixo, de dois frequentadores da The Week - ambos profissionais liberais, brancos, gays e residentes em bairros de classe média alta de São Paulo - resumem bem o modo como a boate é identificada com determinado tipo de público ou com certo padrão de qualidade, tornando-se objeto de desejo para muitos:

A The Week é uma referência. Existe um sentimento inconsciente de que existe um Olimpo, existem os melhores, o grupo ou das bonitas, ou das inteligentes ou do bomgosto, uma elite de sucesso. A referência, os formadores de opinião, o paradigma a ser seguido. A The Week é a boate dessas pessoas. Tem muita gente que não se importa realmente. E tem uma geração que vive em torno do que eles acham que é o mais legal. (entrevista com Igor, 30 anos, em dezembro de 2008).

A The Week é a maior boate gay da América Latina, das maiores do mundo. Eu estive agora na Europa, entrei em boate em Paris, em Londres, em Amsterdam, em Lisboa, nada se parece com a The Week. Eu nunca fui a Ibiza, mas imagino que tenha, mas com o tamanho e qualidade da The Week é difícil. Então, virou meio que o objeto de desejo de todo mundo. Uma vez atrás da revista DOM veio um ingresso VIP pra The Week encartado. Era um tumulto na porta. Um monte de gente. Aí você via essa demanda reprimida. Essa garotada que não tem dinheiro, porque a The Week é cara, morre de vontade de ir à The Week. (entrevista com Pedro, 47 anos, em 


\section{novembro de 2008).}

Na The Week, rapazes de classe média e alto poder aquisitivo - ou aspirantes - viviam a possibilidade de elaborar versões de si a partir da interação com outros rapazes gays de mesma classe social e de experimentar o que consideravam um estilo gay bem sucedido. $\mathrm{O}$ compartilhamento de códigos sinalizados por meio de objetos constantemente visibilizados - como a barra da cueca, em que estava exposta sua marca - era capaz de estabelecer afinidades e barreiras num ambiente em que processos de distinção social pareciam ser muito evidentes. Simbolicamente, a $T W$, numa impressão intensificada por todo o aparato tecnológico da infraestrutura e pela própria grandiosidade do empreendimento, assumia para seus frequentadores o lugar do moderno, do up-to-date, do que havia de melhor e mais sofisticado no mundo gay.

Talvez não por acaso, também, naquele espaço encontrei com mais frequência a valorização do casal 'igualitário' (FRY, 1982; CARRARA e SIMÕES, 2007) associado ao individualismo moderno: exagerando um pouco nas tintas, as parcerias tidas como ideais se davam entre rapazes de mesma idade, mesma cor de pele, mesma classe social e mesma aparência física. A boate era o lugar em que se colocavam em operação intrincadas negociações e barganhas eróticas. A explicação de um interlocutor sobre o capital sexual e sobre a importância da aparência e do corpo, nesse mercado erótico-afetivo, expressa bem a dinâmica das parcerias: segundo ele, quanto mais forte o corpo modelado pela academia, pela alimentação ou por substâncias químicas, maior o capital sexual do indivíduo, o que, num sistema de equivalência, representa maior poder de troca, atraindo também corpos mais valorizados. Como ressaltado, o poder aquisitivo e o capital cultural - expresso pelas roupas certas, pelo domínio do inglês ou pelas viagens adequadas - também entravam nas somas e subtrações que tendiam a valorizar parcerias marcadas pela semelhança. Havia uma forte pressão nas redes sociais para que os parceiros apresentados preenchessem alguns predicados, que poderiam ser resumidos no corpão - no caso de relações efêmeras - e que poderiam, também, estar relacionados fortemente a classe social - no caso de relacionamentos mais duradouros, envolvendo redes pessoais e familiares.

As tensões relacionadas à classe social, envolvendo a The Week e a sua associação, com um público de homens musculosos, jovens, de classe média alta e brancos (que realmente frequentavam o lugar, eram muito valorizados naquele espaço e ocupavam posição destacada na pista de dança, mas dividiam o mesmo ambiente com outros perfis de frequentadores) não passavam despercebidas pelos que se identificavam mais com outros lugares. Tuca - cabeleireiro, estilista e maquiador, negro, gay, frequentador do Boteco do Caê e cuja residência dividia-se entre a casa do namorado, num bairro de classe média alta de São Paulo, e a casa de seus familiares, num bairro popular na grande São Paulo - trazia em sua fala a preocupação em relação ao carão na The Week, especialmente nos tons relacionados a cor/raça que esse carão poderia adquirir:

Quando fomos na The Week, não vi carão nenhum. Todo mundo fala que tem carão. $O$ Carlos, um amigo meu que é negro fala: 'tem, tem carão'. E eu perguntei: 'tem essa questão do carão com o negro? As pessoas olharem de forma diferente?'. Ele disse que sim, que tem muita bicha branca que te olha por cima, mas aí é uma questão de também olhar ela por cima. (entrevista com Tuca, 33 anos, em janeiro de 2008).

O carão, citado por Tuca é categoria nativa e expressa uma atitude esnobe ou de desprezo em lugares de sociabilidade. Pode ser usado, aparentemente, em situações de flerte, em que a menção ao termo é mais comum, ou em quaisquer situações envolvendo interação entre as pessoas em espaços de lazer. No trecho acima, Tuca sugere um jogo entre a bicha branca e a bicha preta (como ele se identifica em outros trechos da entrevista), sendo que a disputa entre os carões indica tensões relacionadas à cor/raça. O carão ${ }^{18}$ pode desempenhar, em determinados contextos, o papel de código que sinaliza exclusões e demarcação de fronteiras entre os perfis valorizados ou não em diversas situações.

É por conta dos significados associados à The Week, especialmente pelos relacionados ao reforço de normatividades envolvendo marcadores sociais de diferença, estilo e padrões de beleza e desejabilidade muitas vezes tidos como próprios do universo gay -, que muitos se recusam a frequentar a boate. Embora tenha eventualmente presenciado na pesquisa de campo um desconforto em relação à boate por parte de algumas pessoas, pude perceber uma recusa mais explícita entre os ursos, que têm um discurso mais acabado de crítica a determinados padrões associados ao universo gay.

Em relação de contraposição direta à $T W$, estavam as festas dos ursos, especialmente a Ursound, iniciativa que vem se apresentando como mais duradoura nesse campo. A festa oferecia um lugar para que os mais gordos e mais velhos se reconhecessem de forma positiva como sujeitos desejáveis e valorizados. 
Ser gordo, mais até do que ser mais velho ou peludo, é uma característica que parece tornar os sujeitos pouco desejáveis no mercado erótico-afetivo de modo geral. Evidentemente, essa não era apenas uma característica relacionada à homossexualidade: padrões de beleza que valorizam a juventude e o corpo de músculos definidos são convenções mais abrangentes. Entretanto, a centralidade adquirida pelo corpo afinado com determinados padrões em algumas cenas gays muito visibilizadas torna a pressão sobre os gordos - e sobre outros que não correspondem ao padrão 'corpo definido ou forte, branco, jovem, de classe média' mais incisiva.

As festas ursinas são consideradas como uma cena alternativa dentro do universo gay, que dialoga e se opõe ao que seria a sua porção mais valorizada. Nesse sentido, os ursos e suas iniciativas ganhariam alguma visibilidade por desafiar determinados 'consensos'19, por comunicarem-se com referências internacionais e por demonstrarem algum nível de organização enquanto 'comunidade', com discussões a respeito da categoria urso e da demarcação de fronteiras e iniciativas para além do lazer noturno (com a criação de revistas, sites, confecções e eventos voltados para esse público). Essa diversidade de ações, bem como a produção de discursos em torno da categoria, faz com que os ursos sejam comumente reconhecidos como um contraponto aos 'consensos' na cena gay.

Nesse sentido, a cena bear ou ursina define-se num movimento que ao mesmo tempo é de contraste com outra cena, tida como padrão, e de afirmação de significados particulares. Esse jogo é evidente nas falas dos frequentadores da Ursound, que sublinhavam as diferenças em relação a outros lugares e marcavam ao mesmo tempo os atrativos da festa, relacionada também a um despojamento nas interações e no vestir que se contrapunham ao que seriam padrões de interação e de consumo mais artificiais ${ }^{20}$ :

Eu descrevo a Ursound como eu, porque me vejo gordinho, eu sou gordinho, um estilo não muito pop. Eu não sou um estilo pop e lá as pessoas tendem a não gostar de um estilo pop também. Eu posso ir de bermuda, legal! Eu posso ir de bermuda, sou eu! Eu adoro bermuda. Usar barba de vez em quando, às vezes eu tiro também, mas eu gosto dessa coisa meio... ah, homem! Meio homem! Que em alguns lugares eu acho que se perde isso, não é um preconceito, mas acho que se perde. E é eu, gordinho, um cara que gosta de usar barba, gosta de usar bermuda, de vez em quando gosta de ir ao teatro ou de futebol, mas às vezes não quer falar com ninguém. Eu vejo isso na Ursound, pessoas mais elas, mais do jeito que elas são. (entrevista com Tadeu, 32 anos, em março de 2008).

As festas dos ursos sinalizavam, então, uma possibilidade de lugar confortável para determinados sujeitos. Como relatou Tadeu em entrevista, a festa é como ele mesmo: gordinho, com um estilo não muito pop, que gosta de teatro e futebol, meio... homem. Assim, aquele espaço permitia a articulação de subjetividades e desejos em torno de características muitas vezes desvalorizadas ou pouco associadas ao 'gay moderno'. Um tipo de masculinidade menos suave, às vezes referida como normal, termo que sinaliza elementos que poderiam ser mais tradicionalmente associados ao masculino em alguns contextos - como a barba, um relativo desleixo nas roupas, a camisa, os gestos mais comedidos, uma saliente barriga - encontrava uma expressão positiva nas festas, trazendo também algum grau de rejeição aos mais femininos e espalhafatosos. Havia ali, também uma relativa diversidade de parcerias, marcadas pela diferença de idade ou aparência física por exemplo, no caso de um homem gordo mais velho que se relacionasse com um rapaz magro - e também pela semelhança - no caso de pares de ursos de mesma idade.

Embora os rapazes que frequentavam a Ursound eventualmente pudessem conhecer a The Week, o contrário não se verificava com tanta frequência nos outros entrevistados. O mesmo acontecia com o samba GLS, outro lugar em que conduzi a observação etnográfica. Por vezes, a própria condução da pesquisa incentivou o trânsito de alguns de meus interlocutores por diferentes lugares: não era raro que eu recebesse, no sábado à noite, telefonemas de pessoas que iam ao Boteco do Caê propondo algum passeio, quando eu já havia me programado para ir à Ursound, o que fez com que eu convidasse esses rapazes a me acompanharem. Assim, alguns frequentadores do Boteco do Caê passaram a frequentar eventualmente a Ursound, da qual tiveram uma impressão positiva, mesmo com eventuais observações de que não tivessem interesse erótico pelos homens que ali se encontravam ou, ao contrário, de que os frequentadores da festa não se interessavam por eles. Mesmo assim, encontraram seu 'lugar' ali, seja chamando a atenção de outros homens, o que acontecia com os que tinham uma aparência corporal e gestualidade tidas convencionalmente como mais masculinas; ou pelo fato de dançarem de forma diferente, incorporando alguns passos de samba rock ${ }^{21}$. Entre os entrevistados, apenas um sabia da existência 
de um pagode gay e também de uma boate black, apesar de nunca ter visitado esses lugares. Via de regra, todos os outros se mostravam bastante surpresos com a existência de um samba GLS, embora não se sentissem curiosos o suficiente para conhecer o lugar.

O lugar em que as classes populares apareceram predominantes, assim como rapazes negros, foi o Boteco do Caê, apelidado carinhosamente de samba gay ou samba GLS. O ar despojado, o espaço para dançar, a relativa indefinição entre a rua e o interior do salão e a cerveja gelada traziam uma atmosfera que atraía os rapazes identificados com o samba e a black music, com forte identificação com as expressões culturais relacionadas à 'negritude' presentes tanto no centro como nos bairros da cidade. Uma complexa negociação se dava ali entre marcadores referentes à cor/raça e a sexualidade, transformando o samba num lugar confortável para a bicha que se via impedida de dançar à frente da bateria na escola de samba e pro mano que não podia flertar com outros rapazes no balanço do samba rock. A frequência aos lugares hetero e gays não deixava de acontecer, mas o samba dos domingos possibilitava um espaço diferenciado de exercício da agência.

No samba foi possível visualizar com maior clareza a figura da bicha popular, posição evitada por boa parte dos homens que acessei durante a pesquisa - e que parece assombrar a todos com a ameaça da vergonha e abjeção social. Encontrei ali uma versão da bicha cujas histórias realmente passavam em certa medida pela vergonha, mas que não se resumiam a isso, falando também de um lugar que trazia vantagens sociais e permitia maior mobilidade - geográfica e social - em relação aos seus pares hetero. Do lado oposto, o rapaz da periferia com aparência masculina e gosto por rapazes semelhantes tinha mais dificuldade na negociação de um lugar confortável e inteligível para si. As parcerias entre os rapazes masculinos eram correntes no samba, especialmente entre aqueles de visual mais próximo do hip hop, que pareciam se interessar por outros de estilo parecido. Apesar disso, o mais comum é que as parcerias se dessem de acordo com um polo masculino e outro feminino, o que não resultava necessariamente na recusa a um desejo de igualdade e de troca - no sentido de compartilhar experiências e ideias - nos relacionamentos.

O motivo que me levou ao samba GLS foi justamente o inusitado da proposta de um espaço dedicado exclusivamente ao samba, frente à predominância das variações de dance music ou da música eletrônica em outros lugares, em que dançar também desempenhava papel importante. A intrincada teia de relações entre diferentes marcadores sociais naquele espaço, bem como a presença de uma estética black, me fizeram continuar indo a campo. Certamente, o samba GLS, apesar de sustentar no nome o termo GLS bastante sedimentado no âmbito do mercado, também desafiava alguns 'consensos' associados aos lugares voltados para esse público. O primeiro diferencial está relacionado à música: se na maioria dos lugares em que dançar desempenha um papel importante - como é o caso dos lugares em questão neste trabalho - a música eletrônica e suas muitas variantes predominam, no samba GLS predominavam o samba, samba-rock e black music.

Intimamente ligado a esse primeiro traço, está o fato de o Boteco do Caê ser um espaço que não apenas é frequentado por homens negros ${ }^{22}$, mas que é reconhecido como tal e que é especialmente voltado para esse público. Durante a pesquisa, não conheci outros lugares que remotamente lembrassem essa proposta. Apesar de todos os lugares aqui tratados apresentarem suas singularidades, em termos de direcionamento de público, a Ursound e a The Week lidavam com a concorrência de iniciativas que disputavam o mesmo público - mesmo que não conseguissem efetivamente ofuscar seu sucesso. No caso do Boteco do Caê, posso dizer que havia outros lugares com frequência predominante de homens negros, mas nenhum que fosse explicitamente identificado ou direcionado a esse público. Talvez mesmo por sua singularidade, quando pensamos nos referenciais acionados pelos frequentadores, para dar sentido ao Boteco, percebemos que este se encontra na intersecção entre lugares GLS e os lugares hetero ${ }^{23}$, o que também é evidenciado por uma circulação bastante intensa do seu público por lugares identificados com uma ideia de negritude ou cuja música se assemelhe à do Boteco. Em entrevista, o proprietário do samba GLS, Caê - empresário, branco, gay, reside numa cidade da grande São Paulo - mostra conhecer bastante bem os atrativos do Boteco e delimita seu público de forma bastante clara como negros homossexuais:

O meu público hoje é baseado nos negros homossexuais. Não que não vá brancos também, vai. Só que o negro é mais presente. Por quê? Em primeiro lugar, é um espaço que eles podem dançar à vontade da forma que eles sabem. Porque o pessoal fica mais solto. Tem os sambas héteros onde o pessoal tem que dançar naquela coisa fazendo estereótipo. Ali, não, ninguém vai estar nem aí. Quer dançar casais, dançam. Nos outros lugares tem que fazer a linha, até porque não é todo mundo que aceita. De repente, se você faz uma gracinha, algum 
imbecil ou até enrustido que morreria de vontade de fazer isso e não tem a coragem vai achar agressivo e querer sair dando porrada. Na escola de samba, não, o pessoal da comunidade é bem resolvido em relação a isso, eles sabem que quem faz o carnaval mesmo, a maioria são os homossexuais, então tem aquele feeling. Mas às vezes o cara tem o namorado e quer dançar com ele e vai dançar como? A proposta do boteco é essa, um ambiente em que você gosta da música e pode dançar com o seu parceiro, seu amigo, e fizer o que der vontade, ficar à vontade. (entrevista com Caê, 35 anos, em março de 2008).

$\mathrm{Na}$ fala, fica claro que o Boteco era uma solução entre os sambas hetero e as escolas de samba e os lugares relacionados a homossexuais, unindo a dança e a música que atrai muitos homossexuais com a liberdade de se dançar como sabe ou ficar à vontade, o que pode ser traduzido a partir da quebra das regras do samba, em que as parcerias se dão entre o homem que conduz e a mulher que é conduzida (casais formados por dois homens são proscritos) e em que há formas de dançar associadas a homens e a mulheres.

Para os entrevistados, o samba GLS também se singularizava mediante o contraste com outros espaços de consumo destinados a gays e com espaços do bairro não marcados como GLS: ali se poderia encontrar no centro uma forma de lazer típica dos bairros mais afastados, que se dá em volta da roda de samba. Era também um lugar GLS para dançar que não está voltado para a música eletrônica, em que não há a presença de drag queens ou a exibição de músculos. Rodrigo, frequentador do Boteco do Caê, e assim o descreve:

Um lugar que eu achei muito legal, tem uma música legal, um samba legal, e o pessoal vai pra se divertir mesmo, aquele batuque, aquela coisa que mexe até com o metabolismo. Já fui em boate, e tal, mas a maioria das vezes eu entrava e passava um tempo, eu me arrependia. Porque lá na boate estava todo mundo, estava aquela reunião de pessoas que eu achava, 'puta, nada a ver', assim.

P: O que você acha que é diferente no Caê, pensando nas boates?

$R$ : É diferente que é um ambiente que a própria coisa da roda de samba e tal, aquela coisa toda, acho que as pessoas estão mais ali para curtir a música e se paquerar e tudo mais, mas num nível assim mais contato humano. Não tem aquela preocupação de ficar o tempo inteiro 'ai, tira a camisa, e é o show de drag, e não sei o quê'. (...) Tem algumas boates que são legais, que rola de ir, por exemplo: lá na Blue Space, tem um ambientezinho que alguns amigos de vez em quando vamos lá, é legalzinho, tal. Mas é legal uma vez por mês ou quando você está muito sozinho, precisa sair pra dar um rolê, as opções são poucas, vou pra uma boate. Então às vezes é falta de opção.

\section{P: Como você analisaria o público do Caê?}

R: Um público mais de periferia mesmo, ou de pessoas que vêm da periferia e vieram morar pra cá. E no Caê encontram aquela coisa que ficou lá na periferia e que ele queria muito ter frequentado mais, mas que por alguns motivos ali do bairro e tal e não sei o que, não conseguia se sentir bem naquele ambiente. Então eu vejo como um ambiente que resgata um pouco a coisa do bairro pra quem está longe do bairro. A roda de samba, aquela coisa das pessoas tomando cerveja e conversando, $e$ conversando mais, e brincando, por mais que exista pessoas no mundo gay que criticam, igual eu já convidei cara pra ir que 'ah, não sei como você vai lá naquele lugar', eu vejo maior lugar bom.

P: Você acha que rola muito isso?

R: Rola. Ah, eu não vou lá, porque lá só vai viado do centro. Do centro, ele quis dizer esses caras que ficam aí na Vieira de Carvalho e tal. Então, não vou lá porque 'é um povinho assim, povinho'. E eu falei 'porra, então, tu não vai, véio, você vai pra boate, assim, e lá talvez você encontre algo que está mais assim, mas eu acho lá no Câe do caralho'. (...) É uma coisa mais humana, tem uma cara até mais brasileira, acho que aquele espaço tem que aumentar. E lá é um lugar bom, não é muito caro, que sai daquela coisa que lugar gay tem que ser caro, igual esses dias eu entrei num site o promoter da The Week falou assim 'agora, nós vamos barrar pessoas na porta, porque a gente não quer aqui dentro da The Week pessoas que pagam a entrada e lá dentro 
não consomem nada'. Isso me deu uma impressão até meio nazista, pareceu uma exclusão, então lugares assim... É legal ter influência, conhecer as pessoas, tem muito isso, assim, mas eu quero ir num lugar pra me divertir". (entrevista com Rodrigo, 26 anos, em março de 2008).

No trecho transcrito, diversos elementos atuam nos significados atribuídos ao samba do Caê: as boates gays, com show de drag, como a citada Blue Space, faziam parte de um cenário em relação ao qual o Boteco afirmava sua singularidade, pela música e pelo contato humano, expresso pelo clima de brincadeira, conversa e mesmo de paquera, em oposição a um ambiente que se supõe o contato entre as pessoas sendo mais pautado pela aparência física e mediada pela apresentação de drags e outros atrativos comuns em uma boate gay 'típica'. Ao mesmo tempo, aproximava-se das rodas de samba do bairro, mas trazia o diferencial de atrair pessoas que, embora tivessem o interesse de frequentar os sambas de bairro, não se sentiriam bem naquele ambiente, o que parecia remeter à sua sexualidade. Simultaneamente, surge a The Week como parâmetro de um lugar gay caro, com um padrão de consumo excludente - impressão essa que se dá via o acesso a um site - e o estereótipo do viado do centro no rechaço ao samba GLS. O trecho explicita as conexões do samba GLS com outras boates, como a mais elitizada The Week e a mais popular Blue Space, com o universo das rodas de samba de bairro e com o público que vai à Vieira de Carvalho, todas derivadas em certa medida, das relações e das referências múltiplas do entrevistado. Assim, a definição de Rodrigo a respeito do Boteco do Caê acionava elementos de sua experiência em boates ou sambas do bairro, mas também conteúdos acessados em sites de outros lugares e de falas em que outros definiam o centro e o Boteco.

Escolhi finalizar este item, com o longo depoimento transcrito acima, por julgá-lo bastante ilustrativo dos diálogos que se davam entre os lugares que compõem o universo pesquisado. Angariando experiências descontínuas no tempo, discursos variados sobre os lugares e fontes de informação diversas, os diálogos imaginados ou concretos eram forjados pelas relações que as pessoas estabeleciam com os espaços de acordo com sua inserção num conjunto mais amplo de lugares. Além disso, os lugares acionavam memórias afetivas e proporcionavam espaços de articulação de subjetividades e de exercício da agência.

\section{Considerações Finais}

Sustentei aqui que a relação múltipla e fluida entre lugares, objetos e pessoas é capaz de mediar e produzir subjetividades, sempre atravessadas por marcadores de diferença social. Apreender relações tão complexas passa também pela compreensão de como as experiências, impressões e significados relacionados aos lugares variam de acordo com as diferentes posições sociais a partir das quais as pessoas se situam.

Esse é um processo de mão dupla: ao mesmo tempo em que as pessoas atribuem sentidos aos espaços, conferindo-lhes uma dimensão simbólica e constituindo-os como lugares, os próprios lugares concorrem para a constituição das pessoas, provendoas de referências e experiências que são contexto para o exercício da agência. Esse entendimento funcionou como um horizonte a partir do qual me foi possível abordar as experiências e interações, proporcionadas pelos lugares aqui mencionados, mas, sobretudo, o movimento pelo qual os lugares transformam-se também em lugares subjetivos, gerando identificação e afeição por parte de seus frequentadores.

Tais relações não são específicas do campo ao qual me dediquei: fazem parte de como as pessoas lidam com os diferentes espaços com que interagem na sua vida cotidiana (MASSEY, 1995; MCDOWELL, 1997). Vale sublinhar, porém, a importância que as atividades de lazer, relacionadas ao consumo, adquirem, na maneira como as pessoas organizam seu 'tempo livre' e estabelecem relações sociais, procurando acessar - ou produzir - um lugar confortável para si mesmas. É preciso, ainda, destacar que, se espaços de lazer são comumente tidos como espaços de liberdade em oposição à casa, à escola, ao trabalho ou ao ambiente familiar, neste caso também figuram como espaços em que se pode viver a dimensão do afeto e do desejo. É nesses espaços que se articula algo como uma ideia de 'poder ser quem se é' por meio de movimentos complexos que alternam 'esforços de normatização e transgressão' (GREGORI, 2010). Como podemos perceber, quando falamos das relações entre pessoas e lugares, tratamos de lugares físicos, mas também de lugares simbólicos e subjetivos.

1 Este artigo resulta de tese de doutorado apresentada em 2010 ao Programa de Doutorado em Ciências Sociais da Universidade Estadual de Campinas / financiada pelo CNPq. 
$2 \quad \mathrm{O}$ uso da expressão 'homens que se relacionam afetivo/sexualmente com outros homens' atende a uma necessidade de nomear os sujeitos que pretendo acessar na pesquisa, conferindo alguma inteligibilidade ao objeto aqui colocado. Esse uso não se dá de forma desavisada a respeito das variações de como esses sujeitos vêem a si mesmos ou das diversas identificações que possam ter, que serão devidamente consideradas no decorrer do texto. Considero também que mesmo as identificações desses sujeitos se dão sempre de forma contextual, a depender de quais questões e atores estão envolvidos em determinada situação, além de quais categorias de classificação se pretende aproximar ou distanciar. Também não suponho que 'sexo' e/ou 'gênero' sejam categorias estáveis e evidentes, considerando toda a discussão na área dos estudos de gênero e sexualidade na direção de questionar os sentidos atribuídos a essas e outras categorias. Sigo aqui a solução utilizada em minha tese de doutorado (FRANÇA, 2010) e que, inclusive, não é original, já tendo sido utilizada por Facchini (2008).

3

Como já argumentou Facchini (2008).

4

Gillian Rose (1995, p. 97) descreve o quanto os sentidos de lugar podem ser complexos: "um sentido de lugar pode ser articulado através de muitos meios diferentes: romances, pinturas, políticas externa ou doméstica, música, filmes, propagandas, as paisagens urbanas e rurais, conversações cotidianas, e muito mais. Os sentidos de lugar podem traçar uma ou mais escalas geográficas: podem ser intensamente locais ou referir ao local e ao global simultaneamente. Um sentido de lugar pode também fazer sentido em relação a mais de um lugar (...). Um sentido de lugar pode funcionar pelo convite a pessoas para a articulação de sua identidade em termos de pertencimento a um lugar particular ou um sentido do que um lugar é pode ser estabelecido mediante um contraste com outros lugares representados como alheios àquele; ou um sentido de lugar pode ser contraditório; ou pode ter pouco a ver com a articulação de identidade. Os sentidos de lugar podem ainda se tornar mais intensos quando aqueles que sentem que pertencem a eles se percebem sob ameaça. Por fim, sentidos de lugar envolvem diferentes grupos de pessoas de diferentes formas. Os mesmos lugares podem se tornar significativos para diferentes pessoas através de diferentes sentidos de lugar".

$5 \quad$ As informações contidas neste parágrafo derivam em parte da extensa revisão bibliográfica realizada por Juliana Mansvelt, em seu livro 'Geographies of consumption' (2005), assim como algumas das referências a seguir. São exemplos de estudos dedicados a espaços 'espetaculares' ou cenários instituídos para o consumo os trabalhos de Warren (1999), Goss (1993) e Erkip (2003). No Brasil, Heitor Frúgoli Jr. (1990) estudou os espaços dos shopping centers como centros de sociabilidade urbana. Alguns dos pesquisadores que se dedicaram a contextos domésticos e práticas de consumo são Miller (2001), Clarke (2001) e Berg (1994). Slater (2000) e Turkle (2002) são dois autores, entre os que têm se dedicado a compreender melhor a produção de relações no ciberespaço. No Brasil, Silva (2008) dedicou-se ao estudo de comunidades virtuais relacionadas à homossexualidade.

6 Estudos como o de Pettigrew (2007) - que investiga como as pessoas atribuem significados a determinadas áreas da cidade e como isso envolve decisões e mensurações do valor da área como um lugar para residência - e de Cuthill (2007) - que compara dois estabelecimentos (um café e um bar) e os significados a eles associados a partir das experiências de consumo que proporcionam aos seus frequentadores - são pouco comuns.

7 No contexto do mercado relacionado à homossexualidade, os espaços de sociabilidade, notadamente as boates e bares, cumprem um papel especial: neles se atualizam referências a respeito da homossexualidade, expressas nos ambientes, na música, nas roupas, nos acessórios, na aparência e apresentação corporal, entre outros. A formulação a respeito do consumo nos lugares está relacionada não apenas ao que efetivamente se consome nesses lugares, no sentido mais imediato do que as pessoas compram dentro de suas fronteiras (bebidas, alimentos, camisetas, cigarros, psicoativos em geral, lugares VIP, serviços de massagem, serviços de estacionamento, entre outros). $\mathrm{O}$ consumo nos lugares passa também pelo uso que as pessoas fazem dos objetos nesses lugares, independente de onde os adquiriram. Dessa maneira, entendo que esteja avaliando o uso dos objetos de consumo e não necessariamente o momento da compra, considerando que esse uso pode revelar significados e mediações que excedem o momento da transação comercial (que também não deixa de ser um contexto útil para a observação e do qual procurei me aproximar na medida do possível). De qualquer forma, no uso que se faz deles nos lugares, os objetos ganham 'vida', caracterizando o processo do consumo, do qual falaremos adiante.

8 Não consegui encontrar um equivalente exato em português para o termo corporatization, que pode 
ser traduzido como privatização (por inteiro ou de partes de um determinado serviço ou produção de mercadorias) e também pode indicar a transformação de algo em um grande e lucrativo negócio, que mobiliza uma estrutura complexa de produção. Acredito que a segunda definição caiba melhor aqui. É também algo que se aproxima da ideia de 'profissionalização', ou seja, da criação de rotinas, estratégias e padrões de excelência relacionados à produção de bens e prestação de serviços.

9 É preciso dizer, ainda, que, se o mercado de lazer noturno responde a dinâmicas próprias de segmentação, isso não é exclusividade desse mercado. Gregori (2010) descreve como há também um processo de segmentação do mercado erótico na cidade de São Paulo, que se revela nas diferenças entre os sex shops do centro da cidade e os de bairros como os Jardins. Os primeiros, concentrariam um público de classe mais baixa, predominantemente masculino; já os segundos, atrairiam um público predominantemente feminino, de classe mais alta.

10 Os autores analisam esse processo a partir de uma perspectiva mais ampla de organização da cidade, que considera a 'vida noturna' como um todo. Ressaltam, assim, a emergência de conjuntos específicos de lugares voltados para gays, para mulheres, para negros, e assim por diante. Penso, porém, que não há problema em transpor a análise pensando na especificação de lugares frequentados por homens que se relacionam afetivo/sexualmente com outros homens, considerando que esses lugares não devem ser tomados como um conjunto homogêneo.

11 Facchini $(2008 ; 2011)$ também encontrou em seu campo de pesquisa, que envolveu os itinerários e os lugares frequentados por mulheres que gostam de outras mulheres, uma tendência à expansão e diversificação, embora o conjunto desses lugares e a circulação de informação sobre eles ganhe dimensão reduzida em relação aos lugares mistos ou voltados para homens. Assim, a autora percebeu, por exemplo, a presença de mulheres mais velhas, de estratos populares e o par feminina/masculina na área do centro e, principalmente, na sub-área do Bixiga. As mulheres mais jovens, de estratos médios e o par feminina/feminina seriam mais presentes nos bares e boates da Vila Madalena. Festas situadas nas imediações da rua Augusta atrairiam mulheres de estratos médios, jovens, que compartilhariam estilos: são as modernas ou minas do rock. Apesar de notar a considerável circulação entre esses lugares, Facchini também notou os limites a essa circulação, que se davam principalmente a partir de classe e geração, mas também dos tipos específicos de parcerias ou apresentação pessoal valorizado nos diferentes espaços, bem como dos códigos de comportamento associados a cada um deles.

12 Se é verdade que esses marcadores podem atuar como tensores libidinais (PERLONGHER, 2005; 2008) e levar integrantes de classes sociais mais abastadas a lugares onde podem encontrar rapazes mais pobres, é também verdade, como vimos, que estabelecem normatividades e produzem fronteiras entre lugares e pessoas.

13 Cada um dos lugares é descrito com densidade na tese de doutorado que dá origem a este trabalho e em outros textos (FRANÇA, 2012; 2010; 2009; 2009a).Para outros trabalhos referentes a lugares de encontro e sociabilidade de homens que se relacionam afetivo/sexualmente com outros homens, ver França, (2006; 2006a; 2007; 2007a). Aqui, lançarei mão apenas de informações essenciais para a compreensão a respeito dos significados que as pessoas atribuem aos diferentes lugares pensando nas possíveis correlações entre eles.

Levando em conta que os sentidos atribuídos aos lugares onde fiz campo são resultado de experiências concretas - mas também imaginadas - de outros lugares, não considero que acompanhar meus interlocutores nos seus fluxos pela cidade e por diferentes espaços seja a única maneira de compreendê-los. Desse modo, procurei não aderir à lógica de que as relações no espaço se dão apenas por meio da contiguidade e da experiência concreta que envolve pisar em determinados territórios, considerando também a diversidade de conexões realizadas pelas pessoas nesse processo.

15 Cabe aqui ressaltar que os intermediários culturais podem responder a forças institucionais variadas, nem sempre representando valores e gostos 'hegemônicos', como pontuam Thompson e Haytko (1997): "as atividades dos intermediários culturais (FEATHERSTONE, 1995) - como publicitários, estilistas, produtores de bens artísticos (música, televisão, cinema), jornalistas, empresários e estrategistas de marketing da moda - fornecem uma conexão comunicativa crítica entre fatores institucionais e a difusão de significados de consumo compartilhados culturalmente. As relações entre a estrutura institucional e significados difundidos é discursiva, mais do que direta, porque um determinado intermediário cultural provavelmente responderia a 
forças institucionais e interesses múltiplos. A natureza discursiva e não determinada dessas relações é tipicamente obscurecida por uma crítica social que interpreta os intermediários culturais como criando e apresentando uma voz quase uniforme de opressivas ideologias econômicas e de gênero". (THOMPSON e HAYTKO, 1997, p. 36).

16 Parte do seu público assíduo caracterizavase pelo acesso e uso de tecnologias de informação, com grande poder de difusão, publicando conteúdos na internet que alcançavam um número de leitores considerável e demonstrando familiaridade com referências internacionais.

17 Vale mencionar que se tratava de um estabelecimento de grande porte, com espaço para 3000 pessoas.

18 Em matéria na coluna Destaques GLS, do jornal Folha de S. Paulo, a bicha carão é associada à cidade de São Paulo e definida da seguinte maneira: "São Paulo é a capital brasileira da 'bicha carão', dizem as drags mais viajadas da cidade. Na gíria, a 'carão' é afetada, esnobe e blasé. Sente-se única, superior. Não anda. Desfila. Jura ter prestígio e bom gosto. Assume ares de poderosa, antenada, descolada, por dentro da moda. Mas despreza pobres, negros e nordestinos. Humilha garçons, porteiros, seguranças, faxineiros". Fonte: Ripardo, Sérgio. São Paulo vira capital do 'gay carão'; leia destaques GLS. Folha de S. Paulo, Folha online, ilustrada, $07 \quad$ mar 2007. http://www1.folha.uol.com.br/folha/ilustrada/ult90u69 127.shtml acesso em 01 set 2009.

19 O que não quer dizer que deixem de criar normatividades nesse contexto ou que não criem outros "consensos", como será explorado no capítulo que trata das iniciativas relacionadas aos ursos.

20 Esses padrões, especialmente no que está relacionado ao vestuário, eram muitas vezes associados pelos entrevistados que frequentam a Ursound com um tipo de 'feminilidade' comum entre os gays, mas que não seria natural aos homens. A rejeição às boates como a The Week ou outros lugares também pode estar ancorada numa ideia de masculinidade que recusa a construção de corpos malhados, depilados ou a composição de estilos de vestuário menos tradicionais. Essa questão foi melhor explorada ao longo da minha tese de doutorado (FRANÇA, 2010), bastando, por enquanto, apenas observar sua ligação com o modo como parte dos frequentadores da Ursound atribuíam significado à festa.
$21 \quad$ Um desses rapazes chegou a ganhar um CD com músicas tocadas na festa de um dos DJs, que justificou o presente dizendo 'nunca ter visto alguém dançar daquela forma na festa'.

22 Embora outras categorias estivessem presentes em campo, a categoria negro foi a mais utilizada pelos entrevistados da pesquisa e outros frequentadores do Boteco quando referiam a si mesmos.

23 Como são chamados os lugares que não são majoritariamente frequentados por homens que se relacionam afetivo-sexualmente com outros homens ou voltados para eles.

\section{Referências}

ANDERSON, Benedict. Comunidades Imaginadas. São Paulo: Companhia das Letras, 2008.

CARRARA, Sérgio; SIMÕES, Júlio Assis. Sexualidade, cultura e política: a trajetória da identidade homossexual masculina na antropologia brasileira. Cadernos Pagu, Campinas, n. 28, p. 65 $100,2007$.

ERKIP, Feyzan. The shopping mall as an emergent public space in Turkey. Environment and Planning A, v. 35, n. 6, p. 1073 - 1093, 2003.

FACCHINI, Regina. Entre Umas e Outras: mulheres, (homo)sexualidades e diferenças na cidade de São Paulo. 2008. Tese (Doutorado em Ciências Sociais). Instituto de Filosofia e Ciências Humanas - Unicamp, Campinas.

FACCHINI, Regina. Não faz mal pensar que não se está só: estilo, produção cultural e feminismo entre as minas do rock em São Paulo. Cadernos Pagu, n. 36, p. $117-153,2011$.

FEATHERSTONE, Mike. Cultura de consumo e pósmodernismo. São Paulo: Studio Nobel, 1995.

FRANÇA, Isadora Lins. Cercas e pontes: movimento GLBT e mercado GLS na cidade de São Paulo. 2006. Dissertação (Programa de Pós-Graduação em Antropologia Social) - Universidade de São Paulo, São Paulo.

FRANÇA, Isadora Lins. Cada macaco no seu galho?: 
arranjos de poder, políticas identitárias e segmentação de mercado no movimento homossexual". Revista Brasileira de Ciências Sociais, v. 21, n. 60, p. 103 115, 2006a.

FRANÇA, Isadora Lins. Sobre 'guetos' e 'rótulos': tensões no mercado GLS na cidade de São Paulo". Cadernos Pagu, Campinas, n. 28, p. 227 - 255, 2007a.

FRANÇA, Isadora Lins. Identidades coletivas, consumo e política: a aproximação entre mercado GLS e movimento GLBT em São Paulo. Horizontes Antropológicos, v. 28, p. 289 - 311, 2007.

FRANÇA, Isadora Lins. Na ponta do pé: quando o black, o samba e o GLS se cruzam em São Paulo. In: BENÍTEZ, María Elvira Díaz; FIGARI, Carlos Eduardo. (Eds.). Prazeres dissidentes. Rio de Janeiro: Garamond, 2009, p. 393 - 424.

FRANÇA, Isadora Lins. Gordos, peludos e 'masculinos': homossexualidade, consumo e produção de identidades em São Paulo. In $33^{\circ}$ Encontro anual da ANPOCS. Caxambu, 2009a. (comunicação).

FRANÇA, Isadora Lins. Consumindo lugares, consumindo nos lugares: homossexualidade, consumo e produção de subjetividades na cidade de São Paulo. 2010. Tese (Doutorado em Ciências Sociais) - Instituto de Filosofia e Ciências Humanas / Unicamp, Campinas.

FRANÇA, Isadora Lins. Consumindo lugares, consumindo nos lugares: homossexualidade, consumo e produção de subjetividades na cidade de São Paulo. Rio de Janeiro: EDUERJ/CLAM, 2012.

FRY, Peter. Para inglês ver: identidade e política na cultura brasileira. Rio de Janeiro: Zahar, 1982.

FRY, Peter. Estética e política: relações entre 'raça', publicidade e produção da beleza no Brasil. In: GOLDENBERG, Mirian (org.) Nu \& Vestido: dez antropólogos revelam a cultura do corpo carioca. Rio de Janeiro: Record, 2002, p. 43 - 66.

FRÚGOLI JR., Heitor. Os shopping centers de São Paulo e as formas de sociabilidade no contexto urbano. 1990. Dissertação. (Mestrado em antropologia social) - Programa de pós-graduação em antropologia social / Universidade de São Paulo, São Paulo.

GELL, Alfred. Recém-chegados ao mundo dos bens: o consumo entre os Gonde Muria. In: APPADURAI,
Arjun (Org). A vida social das coisas: as mercadorias sob uma perspectiva cultural. Rio de Janeiro: EDUFF, 2008, p. 143 - 178.

GOSS, Jon. The magic of the mall: an analysis of form, function, and meaning in the contemporary retail built environment. Annals of the Association of American Geographers, v. 83, n. 1, p. 18 - 47, 1993.

GREGORI, Maria. Mercado contemporâneo de bens eróticos: apontamentos etnográficos e notas sobre gênero e práticas sexuais. In $\mathbf{3 1}^{\mathbf{a}}$ Reunião Anual da ANPOCS, Caxambu, 2007.

GREGORI, Maria. Prazeres Perigosos. Erotismo, gênero e limites da sexualidade. Tese de Livre Docência. Campinas, IFCH-UNICAMP, 2010.

GUPTA, Akhil; FERGUSON, James. Mais além da 'cultura': espaço, identidade e política da diferença. In ARANTES, Antonio A. (org). O espaço da diferença. Campinas: Papirus, 2000 , p. $31-49$.

HOLLANDS, Robert; CHATTERTON, Paul. Producing Nightlife in the New Urban Entertainment Economy: Corporatisation, Branding and Market Segmentation. International Journal of Urban and Regional Research, v. 27, n. 2, p. 361 - 385, 2003.

JACKSON, Peter; THRIFT, Nigel. Geographies of Consumption. In: MILLER, Daniel (Org.). Acknowledging consumption: a review of new studies. London: Routledge, 1995, p. 204-237.

MANSVELT, Juliana. Geographies of consumption. London: Sage: 2005.

MASSEY, Doreen. The conceptualization of place. In: MASSEY, Doreen; JESS, Pet. A place in the world?: places, cultures and globalization. Oxford: Oxford University Press, 1995.

MASSEY, Doreen. Um sentido global do lugar. In: ARANTES, Antônio A. (org.). O espaço da diferença. Campinas: Papirus, 2000, p. $176-185$.

McDOWELL, Linda. Undoing place? A geographical reader. London: Arnold, 1997.

MILLER, Daniel. Behind closed doors. In: MILLER, Daniel (Org.). Home possessions: material culture behind closed doors. Oxford: Berg, 2001, p. $1-19$.

MORT, Frank. Cultures of consumption: 
Espaço, Lugar e Sentidos: Homossexualidade, Consumo e Produção de Subjetividades na Cidade de São Paulo

masculinities and social space in late twentiethcentury Britain. London: Routledge, 1996.

PERLONGHER, Néstor. O negócio do michê: a prostituição viril em São Paulo. São Paulo: Brasiliense, 1987.

PERLONGHER, Néstor. O negócio do michê: a prostituição viril. São Paulo: Perseu Abramo, 2008.

PERLONGHER, Néstor. Territórios marginais. In: GREEN, James; TRINDADE, Ronaldo. Homossexualismo em São Paulo e outros escritos. São Paulo: Unesp, 2005, p. 263 - 291.

PETTIGREW, Simone. Place as a site and item of consumption: an exploratory study. International Journal of Consumer Studies, v. 31, p. $603-608$, 2007.

ROSE, Gillian. Place and identity: a sense of place. In: MASSEY, Doreen B.; JESS, Pat M.. A place in the world?: places, cultures and globalization. Oxford: Oxford University Press, 1995, p. 88 - 132.

SAHLINS, Marshall. Cultura e Razão Prática. Rio de Janeiro: Jorge Zahar, 2000.

SILVA, Carolina Parreiras. Sexualidade no ponto.com: espaços e homossexualidades a partir de uma comunidade on-line. 2008. Dissertação. (Mestrado em Antropologia Social) - Instituto de Filosofia e Ciências Humanas / Universidade Estadual de Campinas, Campinas.

SLATER, Don. Consumption without scarcity: exchange and normativity in an internet setting. In: JACKSON, P. (et al) (Orgs.). Commercial cultures: economies, practices, spaces. Oxford: Berg, 2000, p. $123-142$.

THOMPSON, Craig; HAYTKO, Diana. Speaking of Fashion: Consumers' Uses of Fashion Discourses and the Appropriation of Countervailing Cultural Meanings. Journal of Consumer research, v. 24, n. 1, p. $15-42,1997$.

TURKLE, Sherry. Life on the screen: identity in the age of internet. In: DEAR, Michael; FLUSTY, Steven (Orgs.). The spaces of postmodernity: readings in human geography. Oxford: Blackwell, 2002, p. 455 462.
URRY, John. Consuming places. London: Routledge, 1995.

WARREN, Stacy. Cultural contestation at Disneyland Paris. In: CROUCH, D. (Orgs.). Leisure/tourism geographies: practices and geographical knowledge. London: Routledge, 1999, p. $109-125$.
Recebido em 18 de março de 2012. Aceito em 21 de abril de 2013. 